\title{
Las narrativas del Yo en la crónica contemporánea ${ }^{1}$
}

\author{
Patricia PoBlete ALDAY \\ UAHC-Chile
}

\section{RESUMEN}

En el contexto del actual auge de la crónica en Hispanoamérica, el presente artículo da cuenta de un aspecto característico de ésta: la presencia de un 'giro autobiográfico' (Giordano, 2006, 2011), que no sólo modula la función del texto, sino que implica un recuestionamiento sobre las figuras de autor y narrador, así como de los límites genéricos que tradicionalmente han orientado la labor crítica de la academia. Para ilustrar este proceso se analiza aquí parte de la producción de cinco reconocidos cronistas chilenos: Alberto Fuguet, Rafael Gumucio, Roberto Merino, Francisco Mouat y Pedro Lemebel..

Palabras clave: crónica contemporánea, giro autobiográfico, géneros literarios, cronistas chilenos.

\section{Autobiographical genres in contemporary chronicle}

\begin{abstract}
In the context of the current boom in Hispanoamerican chronicle, this article analyzes a characteristic aspect of this: the presence of an 'autobiographical turn' (Giordano, 2006, 2011), which modulates the function not only of the text but which implies a re-questioning of the author and narrator figures, and generic limits that have traditionally guided the critical work of the academy. To illustrate this process is discussed here from the production of five recognized Chilean contemporary writers: Alberto Fuguet, Rafael Gumucio, Roberto Merino, Francisco Mouat and Pedro Lemebel.
\end{abstract}

Key words: Contemporary chronicle, Autobiographical turn, Literary genres, Chilean chroniclers.

SUMARIO: 1. Alberto Fuguet: retrato de artista. 2. Merino y Mouat: Del recuerdo personal a la memoria colectiva. 3. Rafael Gumucio: crónicas de privilegio. 4. Pedro Lemebel: la intimidad como performance. 5 . Conclusiones.

${ }^{1}$ Esta ponencia forma parte de la investigación realizada en el marco del proyecto Fondecyt de Iniciación $\mathrm{N}^{\circ}$ 11110202, "La crónica periodístico-literaria en Chile: siglo XXI", de la cual soy responsable. 
Si bien es cierto, desde su surgimiento la crónica ha estado cruzada por la subjetividad de un Yo que observa el mundo y enuncia desde un lugar determinado en él, durante los últimos años, en lo que los departamentos de marketing de las editoriales han llamado "el boom de la crónica hispanoamericana", ${ }^{2}$ el peso de ese Yo se ha vuelvo cada vez mayor, modulando de forma evidente la función del texto. Ello no sólo desde el prisma por el cual se observa y filtra la realidad, sino también y sobre todo, desde la inclusión de estrategias escriturales propias de la autobiografía, el testimonio, los diarios de vida y otras narrativas del Yo. Este proceso debe comprenderse en un contexto en el cual los modelos cientificistas y objetivistas han demostrado su insuficiencia, lo que conlleva una revalorización sociológica de la experiencia humana. El ser humano, más que objeto de estudio, se vuelve sujeto activo que construye su identidad por medio de la narración de su vida, lo que explicaría en buena medida el auge de lo biográfico en los últimos años (Klein, 2008), que "absorbe y tritura, cuando no alimenta y promueve, la circulación literaria, periodística, incluso académica" (Giordano, 2011:43).

Este auge de las escrituras autobiográficas, más allá de agudizar la hibridez propia de la crónica, implica una complejización de sus elementos constitutivos, entre sí, pero sobre todo en relación con el contexto sociocultural que los engendra $\mathrm{y}$, en buena medida, los define. Esta inclusión, sin embargo, está lejos de ser homogénea, ya que obedece, entre otros factores, a 1) la relación de la crónica con el resto de la producción textual de cada autor, así como con su proyecto escritural y, 2) la particular posición del autor dentro del campo cultural (Bourdieu, 1992).

Para ilustrar las particularidades de este proceso, nos serviremos de parte del trabajo de cinco reconocidos cronistas chilenos: Alberto Fuguet (1964), Rafael Gumucio (1970), Roberto Merino (1961), Francisco Mouat (1962) y Pedro Lemebel (1955), quienes encarnan — según nuestra propuesta - cuatro puntos reconocibles en la conjunción de las variables antes mencionadas.

${ }^{2}$ Así se lee, p.e. en la huincha roja que acompaña la primera edición de la Antología de crónica latinoamericana actual (2012), editada por Darío Jaramillo bajo el sello Alfaguara: "Un nuevo boom en la literatura latinoamericana." 


\section{Alberto Fuguet: retrato de artista}

Resulta imposible hablar de Alberto Fuguet ${ }^{3}$ sin considerar el contexto en el cual publica sus primeros libros, y la consecuente recepción crítica de los mismos. Sin afán de exhaustividad, recordaremos que a comienzos de la década de 1990, cuando Chile recién cerraba su largo capítulo dictatorial, el compromiso político y social se comprendía aún como un deber cívico y moral, y se esperaba que creadores e intelectuales predicaran con el ejemplo, tal como habían hecho en el pasado, a propósito de hitos como la Revolución Cubana o el mismo proyecto socialista de Salvador Allende. En ese marco, los relatos de Sobredosis (1990) y la novela Mala onda (1991), poblados de jóvenes apáticos y desenraizados; descreídos e individualistas, cayeron como un balde de agua fría. Y es que, paradojalmente, los primeros libros publicados en democracia, los de Fuguet, nos mostraban que la utopía social que se interrumpió con el golpe de Estado era irrecuperable, que nos habíamos convertido en un país-otro, dominado por una economía de mercado que fomentaba el arribismo, el consumo y la fascinación por lo extranjero, en general, y lo norteamericano, en particular. La mutación no era halagüeña, y al dar cuenta de ella, Fuguet acabó siendo su chivo expiatorio. En otras palabras: no se le perdonó que mientras sus colegas mayores experimentaban con el lenguaje para connotar la desintegración del tejido sociocultural provocado por la dictadura, un recién llegado encabezara la lista de best sellers con una escritura veloz y eminentemente referencial, salpicada de marcas de ropa, de nombres de bandas musicales, de drogas duras. Así, con la misma rapidez con la que sus libros se agotaban, su apellido se transformó en un adjetivo; en un rótulo bajo el cual la crítica juzgó con dureza y encono, obviando incluso la más básica distinción literaria: aquella que separa al autor del narrador, y a ambos del protagonista. ${ }^{4}$

\footnotetext{
${ }^{3}$ Su colección de relatos Sobredosis (Santiago de Chile, Planeta, 1990) y su novela Mala onda (Santiago de Chile, Planeta, 1991) lo posicionaron como uno de los referentes principales de las generaciones más jóvenes de la llamada Nueva Narrativa chilena. El prólogo que junto a Sergio Gómez escribiera para la antología McOndo (Santiago de Chile, Mondadori, 1996) desató una intensa polémica entre literatos y críticos, tanto en Chile como en Iberoamérica. En los últimos años, su desempeño cinematográfico - como guionista, productor y director - le ha granjeado un renovado interés del público.

${ }^{4}$ En esta 'confusión' sin duda colaboró la columna Capitalinos, que Fuguet escribió y publicó en el suplemento Wikén del diario El Mercurio, entre 1989 y 1990. En ella, desde la voz ficcional de Enrique Alekán, un treinteañero arribista que trabaja como ejecutivo en una transnacional, se perfilaban los cambios de una sociedad obsesionada con el éxito. Dos décadas más tarde, Fuguet escribiría: "En lo principal -en lo externo- el tipo nada tenía que ver conmigo. Ahora que conozco actores capto que lo que me pasó es lo más parecido a tener un personaje que te come, a toparse con el éxito en un personaje que uno desprecia un resto y que debe ser representado." Véase "Alekán revisited”, en Revista Dossier, 13.
} 
En el caso de este autor, buena parte de sus crónicas pueden (y deben) ser leídas como complemento de su obra de ficción. Lo que encontramos en aquéllas es una suerte de "tras bambalinas" o making off, donde Fuguet repasa el propio proceso creativo desde una posición que oscila entre la nostalgia y la autocrítica. El resultado es una crónica de fuerte carácter auto-biobibliográfico, donde al análisis de la obra en su contexto de gestación y de desarrollo, se le atribuye el poder de revelar la esencia del escritor en cuanto tal (Weintraub, 1991):

Mala onda fue la búsqueda de una voz, de un tono, de un sonsonete, de un registro claro y específico: la voz de Matías Vicuña que, supongo, tiene algo que ver con mi propia voz o, al menos, con la voz que tenía antes que entrara a la universidad. (2007:309)

En "La (primera) película de mi vida", auto-denominada "crónica/confesión" incluida en la antología apuntes autistas, se observa con mayor claridad esta función de la crónica, al enlazar Fuguet causalmente su obra escrita y fílmica. La redacción de la novela Las películas de mi vida (2003) se identifica como un punto de inflexión en su carrera, que lo habría de llevar la gestación y dirección de su primer largometraje, Se arrienda (2006):

[...] lo que estaba haciendo era preparar $\longrightarrow$ pavimentar - mi futuro cinematográfico [...] Siempre quise ser un director; el transformarme en un escritor fue, de alguna manera, no una casualidad, pero sí toda una sorpresa. [...] Ya era la hora, no sabía cómo, pero ya era la hora de dejar de pasarme películas para empezar a hacerlas. (2007:334-335).

La perspectiva utilizada en estos textos es, preferente y evidentemente, la retrospectiva, mediante la cual la crónica se emparenta con la memoria, para hibridarse luego entre la (auto) crítica literaria y el mea culpa público. No es casual que la novela-investigación Missing (2009) se sitúe en este enclave genérico: la complejidad del ejercicio aquí realizado, y la consciencia de los recursos narrativos disponibles, requieren de un autor maduro y, sobre todo, dispuesto a la exposición. La búsqueda del tío que enhebra el relato revela los secretos familiares de los Fuguet, con lo que la fijación del autor con la figura paterna en sus textos previos se hace comprensible y lógica. Vida y obra se unen en un espejo despiadado y redentor, que dificulta y potencia, a la vez, el proceso de escritura.

La misma impudicia —o afán exhibicionista, como acusan los detractores de este autor- se observa en la inclusión de fragmentos epistolares que tienden, igualmente, a la revelación del Fuguet en su gesta creativa. En el citado texto donde

\footnotetext{
${ }^{5}$ Matías Vicuña es el joven protagonista de la novela Mala onda.
} 
narra su experiencia como cineasta primerizo, leemos reproducidos los correos electrónicos que Fuguet enviaba a su equipo de producción; pero, lo que resulta más relevante aquí, es la inclusión de las frases que, en la etapa previa al rodaje, aquél apuntaba para sí mismo en una pizarra, a modo de decálogo de autoayuda. "Es algo patético" (2007:343), reconoce, en el sentido más peyorativo del término, anticipándose al asalto de la crítica. Más allá de la pertinencia ética del gesto —en tanto incluye a otras personas, en este caso, su familia ${ }^{6}$ - la exposición de la propia vulnerabilidad es la que nos permite aunar dentro de la crónica — un modo textual que no es propiamente biográfico - las tres entidades que confluyen, no siempre de forma armónica, en las narrativas del Yo. Autor, narrador y personaje, en virtud del pacto autobiográfico (Lejeune, 1975) se cuestionan y espejean mutua y conscientemente en estos escritos, haciendo de la autorreferencia un proceso complejo y más profundo que la mera contemplación narcisa de la superficie del yo, como acusa la crítica. En este último sentido, acaso para finalizar resulte pertinente recordar que el ritual de observarse al espejo no se agota en la vanidad, sino que connota tanto la necesidad de comprobar la propia identidad ("yo soy"), como de reconocer los propios límites.

\section{Merino y Mouat: Del recuerdo personal a la memoria colectiva}

La inclusión del Yo y sus narrativas en las crónicas de Roberto Merino y de Francisco Mouat se observa principalmente en el recurso a la inclusión de biografemas de los autores (Arfuch, 2002); sin embargo - y aunque los textos de ambos guardan bastante relación entre sí en varios aspectos- dicha inclusión obedece a finalidades distintas, y en función de las cuales ha de ser valorada.

La crónica de Roberto Merino es eminentemente urbana; en ella, el cronistaflanêur se detiene en los detalles cotidianos y escudriña la ciudad de Santiago desde los vestigios de su pasado (principalmente, desde su arquitectura y desde registros textuales como libros o publicaciones periódicas). Estas crónicas dan cuenta de una concepción de la ciudadanía, cruzada por el prisma de lo imaginario, por lo que se la experimenta (y narrativiza) como una poética que enlaza lo actualizado y lo latente; los usos y las representaciones personales y colectivas; el tiempo y los espacios vividos, y también los que ya pasaron (Silva, 1992). Las imágenes de la ciudad, consecuentemente y en palabras de nuestro autor, "flotan a la deriva del inconsciente, son susceptibles de ser reflejadas o transformadas, se superponen entre sí." (2000:146). El recorrido del paseante, que convierte la trama urbana en un

\footnotetext{
${ }^{6}$ En este sentido, el autor recuerda el lanzamiento de apuntes autistas, cuyo capítulo final constituye un embrión narrativo de Missing: uno de los presentadores le pregunta entre bastidores si está loco, y el otro abre la presentación tildándolo de "canalla", por lo impúdico de la confesión familiar. Véase Fuguet, 2009, p. 351 y ss.
} 
trayecto vivido, define una simbología propia, de carácter emocional, tal y como advertía De Certeau (1980).

Con ello, el cronista da cuenta del emplazamiento urbano en su triple estamentación (Auge, 1977): la ciudad-memoria, donde se sitúan tanto los rastros de la gran historia colectiva como los millares de historias individuales; la ciudadencuentro, donde se producen los encuentros tanto entre personas como entre éstas y los lugares que aprendemos a conocer, como si se trataran de personas, lo que propicia la reflexión; y la ciudad-ficción, hecha por imágenes y pantallas, por la cual la urbe aparece como espectáculo.

Desde aquí, el recurso a la propia biografía apunta a evocar un recuerdo colectivo, un 'espíritu de época': el patio trasero de la casona familiar, el insomnio de la niñez y la escuálida vida nocturna de una adolescencia bajo toque de queda, una antigua fotografía, o la propia angustia ante la página en blanco, trascienden la individualidad de la memoria que las atesora para gatillar resonancias en la mente del lector. Así lo vemos, por ejemplo, en un pasaje en el que se recuerda un verano de 1977, cuando a sus 15 años, Merino decide regresar solo a Santiago, abandonando las vacaciones familiares:

Hice escala en Cartagena. Me quedé ahí casi todo el día, caminando por las calles, un poco abismado ante el espectáculo de las copetudas casonas antiguas convertidas en residenciales baratas. La presencia fantasmagórica del pasado se volvía ahí una epifanía básica, al alcance de un niño. (2000:264)

En este sentido, el recurso al impersonal y/o al plural cumple la misma función de despojar al recuerdo de la autorreferencia para fundirlo en un inconsciente colectivo: "A las seis otro timbrazo. Un hombre quiere que nos interesemos en sus cebollas [...] Con el alma en un hilo cerramos las persianas y nos entregamos al zapping." (2000:77). Por medio de estos recursos escriturales, la memoria urbana se presenta como una experiencia pública compartida, esto es, como "una historia en presente" (Ludmer, 2010:114).

Si las crónicas de Merino funcionan como mecanismo activador de la memoria colectiva, dotando de sentido a la ciudad palimpsesto en el mismo acto de revelarlo (esto es: la ciudad que se fue, la que vivimos y la que imaginamos), los textos de Francisco Mouat se articulan desde una indagación sobre las particularidades de ese mismo mecanismo mnemnónico. En esta búsqueda, nuestra condición de habitantes trasciende la trama urbana para adquirir espesor ontológico y universal.

Los textos cronísticos de Mouat se acercan a lo que comúnmente llamamos columna de opinión. De hecho, muchos de los textos cronísticos que nutren sus libros se publicaron originalmente en la revista Sábado, del periódico El Mercurio, donde durante años escribió la columna Tiro libre. Éstos se nutren, en buena medida, de la actualidad noticiosa elaborada por los medios de comunicación, y acaso su mérito capital sea el de volver a convertir la información en experiencia 
significante. Por ello, podríamos sostener que Mouat se constituye como un narrador anacrónico: esto es, en el sentido benjaminiano del término. A propósito, y desde, el rescate de los treinta y tres mineros chilenos, en octubre de 2010 , el autor se pregunta:

¿Es verdad que nos importa la vida y el destino de estos treinta y tres hombres? Yo creo que no. Antes de quedar encerrados en la mina por el derrumbe, yo apenas sabía algo de uno de ellos, Franklin Lobos, porque era futbolista y uno lo vio jugar. Y no creo que mi caso sea una excepción. Nos alucina la fuerza de un ser humano expuesto a una situación límite, su capacidad para luchar, pero no creo que nos importe demasiado el destino de estos hombres que volvieron a la superficie de la Tierra. (2011:217)

Pero quizás donde mayor profundidad alcanza esta interpenetración entre la superficie de la actualidad noticiosa y la persistencia significante de la realidad, sea en El empampado Riquelme (2001), crónica extensa que narra la investigación que Mouat realiza para procurar establecer las razones de la desaparición de Julio Riquelme Ramírez en el desierto de Atacama. La búsqueda, que se inicia en apariencia por razones netamente periodísticas, gatilla una revisión autobiográfica y una reflexión donde resuena un tema universal: el padre como figura rectora y ambivalente, que suscita tanto amor como rechazo. Leemos, en el capítulo 13 ("Papá de viaje"):

Nos costaba hablar. Siempre nos costó. Yo con mi silencio no ayudé mucho. Él tampoco se esforzó en quebrarlo. Entre los dos se interponía en las mañanas infantiles en que me llevaba al colegio la voz inconfundible de Jimmy Brown en la radio, los chistes fomes del ciego y piezas de música clásica que no valía la pena interrumpir. Ése fue nuestro estilo de convivencia. Jugábamos poco juntos. Y normalmente había cosas que hacer durante los fines de semana. Ir a comprar parafina en invierno, en bidones de quince y veinte litros, para llenar un maldito tanque que alimentara a las tradicionales estufas Comet. Ir a la feria de Tobalaba los sábados en la mañana y ayudar a cargar bolsas (2008:124-125)

De este modo, tanto el recuerdo autobiográfico como la contingencia noticiosa confluyen en una memoria $^{7}$ o imaginario colectivo, densificando emocionalmente la carga semántica de las palabras. En la exhibición de pasajes de la propia vida, y la reflexión que desde ellos se propicia, el Yo trasciende su singularidad para fundirse,

\footnotetext{
${ }^{7}$ Recurro aquí a la distinción entre la memoria como función de la conciencia, y el recuerdo como acontecimiento que remite a la unidad del sujeto. Vid. Giordano, 2006.
} 
en la lectura, con otros. Ejercicio performativo - autorial, a fin de cuentas - en este proceso la memoria es asumida como un arte poética y un imperativo moral, y su ejercicio en estas crónicas viene a ser un intento de vislumbrar lo esencial tras la sobresaturación informativa:

En un día cualquiera de nuestras vidas computamos miles de señales: palabras, gestos, colores, miradas, olores, emociones, gritos, hambre, murmullos, sabores, frenadas de auto, puntadas, silencios, texturas, risotadas, fatiga. Y no nos detenemos, ni siquiera en el sueño. Somos un barril sin fondo, y entonces, para no volvernos locos, para sobrevivir, seleccionamos unas pocas cosas a las cuales verdaderamente ponerles atención y el resto es una buena dosis de indiferencia ante todo lo demás. (2008:95)

La labor cronística de Mouat se comprende en toda su amplitud, y ambición, desde esta perspectiva, como la búsqueda de atisbos de experiencia absoluta, de "iluminaciones profanas". En esta tarea, la fragmentación, la dispersión y heterogeneidad formativa propias de estos textos se entienden, menos que como marcas de una estética posmoderna, como una escenificación del mismo movimiento de la memoria, que vaga entre temas, objetos, tiempos y espacios.

\section{Rafael Gumucio: crónicas de privilegio}

Descendiente de una familia de influyentes políticos e intelectuales chilenos, Rafael Gumucio pertenece a la "casta de los elegidos, de los autoelegidos que siempre tienen algún tío que les dé un préstamo, que siempre tienen un puesto que les espera" (2002:25). Su mirada enfoca la cotidianidad nacional desde la macro perspectiva de los procesos sociales e históricos, antes que desde el detalle de los hechos noticiosos, dialogando tanto con la tradición cronística de Indias como con la de los cuadros de costumbres. En este entramado, el recurso a la biografía del Yo autor/narrador (particularmente, a sus aspectos excepcionales) genera una mirada excéntrica, que cuestiona y emplaza al entorno en virtud precisamente de la conciencia —aguda y problemática — que posee de su propia excepcionalidad.

"Soy impune, soy libre, soy aristócrata" (2010:98), se jacta autoirónicamente Gumucio. Su historia, la historia de su familia, resulta inseparable de la historia de Chile, y esa filiación parece ser suficiente para autorizar y justificar la recurrencia autobiográfica. Su adagio egótico espejea el de uno de los grandes maestros de la crónica, Truman Capote: "Soy drogadicto, soy homosexual, soy un genio". Y la emulación no sólo es a nivel sintáctico, porque la genialidad, en tanto herencia/yugo familiar y promesa incumplida, será el punto que señale el derrotero de la particular hybris de este cronista: "Quiero ser un genio o no ser nada, o más bien, tengo miedo de que si no soy un genio puedo llegar a ser nadie" (2010:15). 
[...] no quiero ser otra cosa que aquello para lo que me he entrenado interminablemente: genio. Pero no voy a ser eso tampoco, voy a ser un chileno más. Alguien que casi fue un dios y que limpia la parrilla el sábado para invitar a los amigos el domingo. (2010:135)

Desde esta particularidad enunciativa, la narración adquiere una función que podríamos considerar psicoanalítica, en virtud de la cual el cronista vuelve al pasado histórico en busca de aquellos episodios traumáticos que pueden explicar la parábola del fracaso individual y el de toda una generación. Es el ejercicio que aúna los textos de Memorias prematuras (1999), Monstruos cardinales (2002), Los platos rotos (2004) y Páginas coloniales (2006). El golpe de Estado y Pinochet; la separación de los padres; la dislexia que el autor padece; don Francisco monopolizando la tarde del sábado desde el televisor; los terremotos; el exilio o sus dientes muertos son pruebas que Gumucio acumula y exhibe en busca de su propia exculpación. "La dictadura me hizo así" (2002:27), reza el título de una de sus crónicas. O, aún más explícitamente: "Si, como dicen los psiquiatras, el rol del padre es separar al niño de la inconsciencia y lanzarlo al mundo, yo soy hijo de Pinochet" (2004:135). Pinochet, padre déspota de la horda primitiva, muere y deja a sus vástagos huérfanos, condenados a vagar por una infancia donde se enraíza y crece el daño, del que únicamente se tomará conciencia a posteriori. Así entendemos la recurrente identificación del narrador con un niño, que aterrorizado ante el imperativo de hacerse adulto, se escuda en la megalomanía y en el delirio de genialidad. Su escritura, antes que todo, da cuenta del choque entre esa conciencia individual y el mundo:

\begin{abstract}
Atravieso los años, estudio sin estudiar, todos los años se repite mi promedio 5,5, paso a duras penas la universidad, sigo tratando de impresionar a cualquier precio, sigo gritando y rogando, sigo, con una timidez infernal, gritando a quien quiera escucharme. Hago lo posible para que me amen, tartamudeo y hablo por radio y televisión, no sé escribir dos palabras sin una falta de ortografía y escribo en los diarios, en las revistas, en los libros, todo por impresionar. (2010:30)
\end{abstract}

De esta forma, contrario a la corriente principal de crónicas contemporáneas, que se legitiman desde la visibilización del Otro silenciado tradicionalmente por los discursos hegemónicos, en los textos de Gumucio, el Otro es el privilegiado, quien en la excepcionalidad de su historia de vida encuentra y exhibe el fermento de su mirada irónica y autoflagelante.

\title{
Pedro Lemebel: la intimidad como performance
}

En esta somera revisión de algunas de las modalidades y usos de la inclusión de las narrativas del Yo dentro de la crónica contemporánea, el caso de Pedro Lemebel resulta particularmente atractivo, ya que se aprecia una diferencia sustancial, en este sentido, entre el grueso de sus publicaciones y algunas de las más recientes. En 
aquéllas la función narrativa se orienta preferentemente a la focalización de ciertas parcelas de la realidad negadas u oscurecidas por los discursos oficiales, en especial la experiencia de una triple marginalidad: la de las minorías sexuales, la de la pobreza y la de las culturas originarias. Esto, como ha sido vastamente estudiado, constituye el foco enunciativo, y reivindicativo, de la prosa de Lemebel. En estas crónicas los biografemas se funden en la experiencia colectiva, adquiriendo por lo mismo función testimonial y activando su código de recepción veridictivo (Ochando, 2008), que demanda del lector no sólo la aceptación de lo narrado en tanto realidad, sino además una toma de partido ideológico ante ella.

Por ello, la vida reflejada en la literatura testimonial no pertenecería al ámbito privado, sino al social, y no buscaría - como en el caso de las memorias o los diarios- la significación íntima de los sucesos narrados, en el marco de una sola existencia, sino que más bien apuntaría a la denuncia de injusticias que afectan a colectividades, y a la demanda de una transformación social. Lo mismo vale para la narración de experiencias individuales que se atraviesan por acontecimientos colectivos (como la celebración de fiestas navideñas o hitos nacionales): esto, más que a un ejercicio de autorreferencia, correspondería a una 'ritualización de recuerdos compartidos' (Klein, 2008), que vuelve a legitimar el recuerdo al interior de una colectividad, y a hacerlo narrable.

Sin embargo, buena parte de las crónicas incluidas en Adiós mariquita linda (2005) y Háblame de amores (2012) tematizan episodios personales, de carácter amoroso-sexual, donde la especificidad de lo narrado no atañe más que al propio Yo. Aquí Lemebel, en el gesto de escribir - y sobre todo de publicar- pasajes privados de su vida, hace de su intimidad un espectáculo, una performance (acaso emulando las intervenciones de las Yeguas del Apocalipsis en los '80) que desafía la función de la crónica, en general, y su ejercicio particular previo, orientado como veíamos, hacia el testimonio. Es imposible dejar de notar la correspondencia de este giro con el desplazamiento de Lemebel dentro del campo cultural chileno, por el cual se ha convertido, durante los últimos años, en un actor relevante, que dotado de distinción y respetabilidad, circula por ferias del libro, dicta charlas en museos y universidades del extranjero, y goza de becas para la creación artística.

Esta conjunción del Yo público y el Yo íntimo se ilustra notablemente en el texto "Luna de Barranquilla que me hiciste sangrar" donde, en el marco de su viaje como invitado al festival de las artes de esa ciudad, detalla el encuentro sexual con el bello prostituto que le reserva (y paga) la producción del evento; y, sobre todo, se ufana del hecho de que el chico lo prefiriera a él antes que al escritor colombiano Fernando Vallejo:

Vallejos [sic] hablaba con alguien y al verlo quedó tartamudo. No lo podía creer, trataba de decir algo y se le cayó la copa de la mano. ¿Cuánto te pagan?, fue lo primero que se le salió. ¿Cuánto te paga Lemebel?, insistía grosera, abalanzándose encima mío para alcanzar la mano del guapo. Tú me conoces a mí. 
Yo soy el autor de La Virgen de los sicarios. ¿Viste la película? Te pago en dólar, el doble, el triple. [...] El joven miraba a uno y a otro sin saber qué decir. Mira, vieja ordinaria, enrostré a Vallejos [sic], soy visita y él es una atención. No me importa, dijo Vallejos [sic] sin ningún pudor, y volvió a la carga.[...]

A mí me trajeron para atender al señor Pedro, dijo el pendex al fin con un suspiro [...] Viste lo que te pasa por apresurada y jactanciosa, le dije en el oído al gran Vallejos [sic] que, sin inmutarse, se paró en busca de otro vaso. Por esa noche, Vallejos [sic] había desaparecido y ya de regreso al hotel, Jonathan se ponía el preservativo para ensartarme el cometa morocho de su enorme sexo hirviendo. (2012: 47-48)

Con la misma impudicia con la que Lemebel muestra a sus anfitriones, a la mañana siguiente, "los rubíes encarnados que manchaban la sábana blanca" (2012:48), estos textos buscan acaso horadar una moral supuestamente conservadora, utilizando para ello la misma estrategia que rige la actual sociedad del espectáculo: "la reducción por escrito de la privacidad a mercancía y fetiche" (Giordano, 2011:44). Así comprendida, la autorreferencia se vuelve paradójica estrategia de subversión, que en el mismo acto de complacer el morbo del público consumidor, en el exceso exhibicionista violenta su "sermón putifrunci" (2008:270), y muestra cómo el resguardo de la decencia y las buenas costumbres, pierde afán ante el peso del mercado.

\section{Conclusiones}

Con una alarmante generalización dentro de los estudios literarios chilenos de las últimas décadas, el giro del sujeto hacia sí mismo (giro subjetivo o giro autobiográfico, como lo llaman Beatriz Sarlo y Alberto Giordano, respectivamente), ha sido interpretado como un mero reflejo de esa cultura del narcisismo que según nos han dicho- signa la contemporaneidad (Lasch, 1979). No podemos negar que el contexto o clima de época fomentan el desarrollo de las narrativas del Yo, pero sobre ese entendido, pocos han sido los que se han dado el trabajo de analizar qué hay tras esa simple y aparente correspondencia; qué función cumple el Yo dentro del texto, o cómo ello se manifiesta específicamente en la crónica, y afecta su lectura.

Las inclusiones del Yo dentro de esta modalidad textual configuran un momento autobiográfico (De Man, 1979) o espacio biográfico (Arfuch, 2010), comprendidos como una serie de desplazamientos retóricos (como los que aquí hemos revisado), que tienden a lo biográfico sin constituirlo por completo. Esta particular forma de hibridez conjuga espacios y estrategias de enunciación; modalidades textuales canónicas y productos de la cultura de masas; subjetividades múltiples que concurren en los distintos momentos de producción y lectura del texto; $\mathrm{y}$, sobre todo, la activación conjunta de horizontes de expectativas provenientes de distintos registros textuales. Muy brevemente, distinguiremos las consecuencias de este proceso en tres ámbitos que nos parecen esenciales: 
a) Estatus realidad/ficción. Superada la división que reservaba el ámbito de lo real para el ejercicio periodístico, y el ficcional para la literatura, el giro autobiográfico en la crónica contemporánea implica un replanteamiento de lo íntimo y lo auténtico, en un contexto en el cual lo público y lo privado ya no constituyen esferas puras ni necesariamente antagónicas. Si tradicionalmente la vida "verdadera" se vivía en el reducto de la privacidad, dicho estatus de autenticidad hoy se relativiza; a la vez que lo íntimo se va constituyendo en el espacio ambiguo que amalgama lo público y lo privado. A eso debemos sumarle los ejercicios de autofabulación en los que el Yo incurre al explorar su individualidad dentro del texto, siendo consciente de la mirada de un público lector que, a fin de cuentas, y en rigor, mediante la lectura acaba de transformarlo en personaje.

b) Posición del autor. Los cronistas coinciden en señalar la relevancia del desarrollo de un punto de vista personal dentro del texto; sin embargo, antes que por la mirada, la crónica que aquí hemos analizado se sustenta en un nombre, o mejor aún: en una firma. La inclusión de fragmentos autobiográficos o digresiones personales es un lujo que pueden darse los cronistas reconocidos, que gozan de cierto estatus privilegiado dentro del campo cultural o literario, y que por lo general son convocados por los periódicos o las editoriales para publicar crónicas en virtud, precisamente, de esa posición.

c) Horizonte de expectativas para la crítica. La flexibilidad que nos exige la crónica actual en tanto lectores, en general, y muy en particular, en tanto críticos y estudiosos, implica reconocer que, más allá de su mentada y no siempre analizada hibridez, hablamos de una forma textual proteica, que ajusta constantemente su fisonomía para dialogar con el medio que la propicia y en el cual se desarrolla. Por lo mismo, los trabajos de quienes estudiaron la crónica en el pasado (Rama, 1984; Ramos, 1989; Rotker, 2005) sientan una base valiosísima y proporcionan líneas guía fundamentales, pero no se ajustan necesariamente al tipo de textos que hoy se escribe y publica. Entre cruces genéricos, transformaciones textuales y referencialidades ambiguas — lo que Ludmer (2010) ha llamado el espacio de las literaturas post-autónomas - ante la crónica actual no cabe ensayar definiciones ni proponer taxonomías sino, al menos de momento, tomar palco y especular sobre el sentido y la función que van adquiriendo estos procesos en desarrollo.

\section{BIBLIOGRAFÍA}

ARFUCH, Leonor.

2010 El espacio biográfico. Dilemas de la subjetividad contemporánea. Buenos aires: FCE [2002].

AUGE, Marc.

1998 El viaje imposible. El turismo y sus imágenes. Barcelona: Gedisa. 
BOURDIEU, Pierre.

2005 Las reglas del arte. Génesis y estructura del campo literario. Barcelona: Anagrama.

Certeau, Michel de.

1996 La invención de lo cotidiano. Vol. 1: Artes de hacer. México: Universidad Iberoamericana.

FUGUET, Alberto.

2007 apuntes autistas. Santiago de Chile: Aguilar.

2009 Missing (una investigación). Santiago de Chile: Alfaguara.

GIORDANO, Alberto.

2006 Una posibilidad de vida. Escrituras intimas. Buenos Aires: Beatriz Viterbo Editora.

2011 Vida y obra. Otra vuelta al giro autobiográfico. Buenos Aires: Beatriz Viterbo Editora.

GuMUCIO, Rafael.

[1999] 2010 Memorias prematuras. Santiago de Chile: Random House.

2002 Monstruos cardinales. Santiago de Chile: Sudamericana.

2004 Los platos rotos. Historia personal de Chile. Santiago de Chile: Sudamericana.

2006 Páginas coloniales. Buenos Aires: Mondadori.

KLEIN, Irene.

2008 La ficción de la memoria. La narración de historias de vida. Buenos Aires: Prometeo Libros.

LASCH, Cristopher.

1999 La cultura del narcisismo. Santiago de Chile: Andrés Bello.

LEJEUNE, Philippe.

1991 "El pacto autobiográfico", en Ángel Loureiro (coord.), La autobiografía y sus problemas teóricos. Barcelona: Anthropos, pp. 47-61.

LEMEBEL, Pedro.

[2003] 2008 Zanjón de la aguada. Santiago de Chile: Seix Barral.

2005 Adiós mariquita linda. Santiago de Chile: Sudamericana.

2012 Háblame de amores. Santiago de Chile: Seix Barral.

LUDMER, Josefina.

2010 Aquí, América Latina. Una especulación. Buenos Aires: Eterna Cadencia.

MAN, Paul de. 
1991 "La autobiografía como desfiguración”, en Ángel Loureiro (coord.), La autobiografía y sus problemas teóricos. Barcelona: Anthropos, pp. 113-118.

MERINO, Roberto.

2000 Horas perdidas en las calles de Santiago. Santiago de Chile: Sudamericana.

MOUAT, Francisco.

[2001] 2008 El empampado Riquelme. Santiago: De Bolsillo.

2008 La vida deshilachada. Santiago de Chile: Debate.

2011 Calendario 2008-2011. Santiago de Chile: Lolita Editores.

OCHANDO, Carmen.

2008 La memoria en el espejo. Aproximación a la escritura testimonial. Barcelona: Anthropos.

RAMA, Ángel.

2004 La ciudad letrada. Santiago de Chile: Tajamar.

RAMOS, Julio.

1989 Desencuentros de la Modernidad en América Latina: literatura y política en el siglo XIX. México: FCE.

ROTKER, Susana.

2005 La invención de la crónica. México: FCE/Fundación para un Nuevo Periodismo Iberoamericano.

SILVA, Armando.

1992 Los imaginarios urbanos. Bogotá: Tercer Mundo Editores.

WEINTRAUB, Karl.

1991 "Autobiografía y conciencia histórica”, en Ángel Loureiro (coord.), La autobiografia y sus problemas teóricos. Barcelona: Anthropos, pp. 18-32. 